\title{
Gender Perspectives on Mathematical Content Preferences at Secondary Level
}

\author{
Hom Kumari Adhikari \\ homaadhikari1@gmail.com \\ Lecturer \\ Central Department of Education, T.U., Kirtipur
}

\begin{abstract}
This study was conducted to examine student's preferences on mathematical content area and contents within each content area at secondary level. The respondent were 60 students, including 33 girls and 27 boys, who were selected using stratified random sampling method. Descriptive survey design was used with the help of survey questionnaire. Data were analyzed using descriptive statistics (Mean and Std.) and inferential statistics (t-test). The result of the study revealed that Set was the most preferable content area in mathematics in compare to other area for both boys and girls. Whereas, boys least preferable and difficult area was Geometry, while girls was Probability. Most important contents for their future life were Arithmetic related contents in comparison to other contents within content area. Likewise, the study found that the mean difference between boys and girls was not statistically significant with preferences in overall mathematical content area and overall contents within content area. Similarly, there was not significant differences exist between boys and girls with preferences in each content area and every contents within each content area except one content of Arithmetic.
\end{abstract}

Keywords: Preferences, Content Area, Gender, Mathematics, Geometry

\section{Introduction}

Gender is an emerging issue in all over the world. Nepal is one of the developing country on which still gender disparity found in mathematics. We have found gender differences between boys and girls on mathematical performance and achievement except this on preferences of mathematical content area and topics within each content area in mathematics. I have met some people in my student life and in my teaching career, they told me that they did very well in geometry but felt more terrible at algebra and vice versa. Similarly, such types of differences also found in other content area in secondary school mathematics. That issue motivates me to conduct research on this topic. The main purpose of this study was to examine girls' and boys' mathematical content preferences at secondary level.

This study investigated what mathematical content area value by boys and girls in Nepalese schools with regard to mathematics teaching learning process. It examines students' satisfaction with the difficulty level of mathematical content area and also examine the importance of 
contents within each content area for their later life. In this study, the focus of this study would be on how similarly or differently boys and girls satisfy towards mathematical content area and feel important the contents within each content area for their future life.

Large number of studies examined based on boys and girls mathematics achievement and performance, although most of the studies indicating that boys are more successful and outperformed girls in mathematics (e.g., Asante, 2010; Fryer Jr \& Levitt, 2010; Stoet \& Geary, 2013). On the other hand, many studies examining girls are more successful in mathematics than boys (e.g., Chambers* \& Schreiber, 2004; Farooq, Chaudhry, Shafiq, \& Berhanu, 2011). Furthermore, most of the research studies found there were no gender differences between boys and girls on mathematical achievement (e,g., Bulut, Gür, \& Sriraman, 2010; Chiesi \& Primi, 2015, February; Else-Quest, Hyde, \& Linn, 2010; Hyde, Lindberg, Linn, Ellis, \& Williams, 2008; Lindberg, Hyde, Petersen, \& Linn, 2010).

Mathematics is a compulsory subject up to grade $\mathrm{X}$ for all students in Nepalese curriculum. There are eight content areas such as Set, Arithmetic, Mensuration, Algebra, Geometry, Trigonometry, Statistics, and Probability at grade IX and X mathematics curriculum in Nepal. In Nepal, NASA result at different grade in different year had showed some differences on performance of mathematics as a whole and content wise between boys and girls. Moreover,NASA result 2012 and NASA result 2015 of grade III found that there were no statistically significant differences in achievement between boys and girls in any mathematical content area of both community and institutional school (Education Review Office, 2015, 2016). But, NASA result 2012 and 2015 of grade $\mathrm{V}$, showed significant differences between boys and girls mathematics achievement and in all mathematical content areas boys outperformed girls (Education Review Office, 2016). In comparison to the data set of 1999 this differences between boys and girls is narrow but differences exist according to gender. Similarly, NASA result 2018 of grade V showed still boys outperformed girls by 2 scale score in mathematics, but differences was very narrow. This result indicated the positive signal of gender parity at primary level. According to this NASA report upto grade III, there were no gender differences between boys and girls but differences started to exist in mathematics performances from grade $\mathrm{V}$ in Nepal.

Similarly at grade VIII, NASA result 2011 and 2013 showed significant differences between boys and girls achievement in mathematics whereas in all content areas boys outperformed girls but both boys' and girls' mathematics achievement decreases from the year 2011 to 2013 (ERO, 2015). In addition, according to ERO (2015) NASA result of 2013 compared with TIMSS indicated that Nepalese students were very weak in mathematics. These data showed that at secondary and higher level, gender differences would found greater than the previous level in mathematics. The data of district of examination (DOE) of 2008 of grade V and VIII at national level examinations showed boys do slightly better in Mathematics, while girls do slightly better in English and Nepali and girls' and boys' average scores were the same for both Science and Environment and Social Studies (Terry \& Thapa, 2012).

Most of the students do not equally satisfy to all content areas. They feel some mathematical content area would be more important for their daily life and hence they prefer such type of 
content. In Statistics, girls were less confident about their ability, perceived it more difficult, and had negative attitude in comparison to boys, moreover, both boys and girls did not differ in terms of their mathematical ability (Chiesi \& Primi, 2015, February). Two mathematical content area such as Probability and Statistics are interrelated to each other and interact with real-life problems and helpful in other disciplines. But in teaching and learning process, most of the teachers and students feel various difficulties and secondary teachers expressed probability as the most difficult subject in the mathematics curriculum (Okan \& Arican, 2020).

Boys and girls are motivated towards mathematical content area due to their personal goals. We found gender differences between boys and girls in the preferences of mathematics content area and topics within each content area. In mathematical content area especially girls preferred algebra whereas boys preferred geometry (Uwineza, Rubagiza, Hakizimana, \& Uwamahoro, 2018). Additionally, Uwineza, et al. (2018) expressed that girls prefer mathematics units that require just application of formulas on the other hand boys prefer mathematics units requiring reasoning to strength then their confidence. Likewise, in probability and geometry, boys are more successful than girls (Bulut, et al., 2010). In the study of Barkatsas, Law, Seah, and Wong (2019) it was examined that girls favor a more collaborative learning environment and less valuing to problem solving, whereas boys prefer more competitive and problem solving learning environment.

In Nepal, NASA result 2013 of grade VIII expressed that students performed poorly in algebra $(28 \%)$ and geometry (34\%) which is less than national mean (35\%) in mathematics (ERO, 2015). Moreover, Boys outperform girls in more complex area of mathematics like as more advanced problem solving but fewer gender differences are found on the more basic numerical skills between boys and girls (Ganley \& Lubienski, 2016). On the other hand, boys perform better on numerical or arithmetical performance whereas girls perform better on language usage (Le Grand, 2015). There was statistically significant differences between boys' and girls' valuing of mathematics learning found on three out of nine component (Barkatsas et al., 2019). They reported that boys valuing meaningfulness and positive attitude more than girls while, girls valuing autonomy more than boys in learning mathematics.

Likewise, NASA result 2012 of grade III expressed student's weak result in Algebra (40\%) than Arithmetic (61\%) and Geometry (60\%). Likewise, grade V students were somehow weaker than the average (53\%) in Numeracy (44\%) and Algebra (49\%) than average in Geometry (57\%), and Arithmetic (54\%) (Education Review Office, 2015).NASA result 2011 of grade VIII students showed that average learning outcome of students were weaker in Geometry and Sets rather than arithmetic, Algebra, and Statistics (ERO, 2013). These result showed that students were good in Geometry at basic level but after grade VIII they going to become weaker in Geometry. Amelink (2009) Girls prefer the subjects related to computation, reading graphs, algorithmic problem solving on the other hands boys prefer mathematics activities related to word problems, visual spatial skills, problem solving, reasoning, proportionality, measurement and problems no immediate formula. Additionally, girls do better in mathematics that deals with direct application. Likewise, males outperformed females on different mathematics content domains such as number, geometry, and data and chance. 
The rational of this study is that it would provide us with new knowledge about mathematical content area in school mathematics. It acknowledges us about boy and girl students' preferable mathematical content area and contents within each content area. This study also acknowledge us about the contents important for boys and girls for their future life. It would provide better understanding to teachers, curriculum designers, policy makers, school administration, etc. about how engage students in different content area in school level. Teachers would have better understanding about girls' preferable mathematical contents and also to boys. Accordingly it helps teacher to conduct teaching learning process on mathematics classroom based on gender specific learning needs. The motivation to conduct this study was determined by the fact that there are still very few number of research conducted through gender perspectives about mathematical content area in the education system of Nepal. The findings of this study may bring changes on teacher's classroom activity, mathematics curriculum, education planning, and teaching methods in Mathematics.

\section{Theoretical Framework}

Liberal feminist theory. The feminist theory focused about gender inequality, which is not an individual matter but is inherently affected by the structure of the societies. Gender inequality is built in families, societies, culture, polities, religions, and varieties of languages we speak (Zarza, 2018). It is necessary to make both male and female equal, but it is social solution not an individual solution. There are three broad categories about feminist perspectives with regard to the gendered social order: gender reform feminisms, gender resistant feminisms, and gender revolution feminisms (Letherby, 2003). Liberal feminism, of the second wave of feminism of the year 1960's and 1970's, were based on gender reform feminism. In this study, I standed on liberal feminism under gender reform feminism.

Liberal feminist theory commands equal treatment for both boys and girls and seek to build up same opportunities and rights to both (Thompson, 2003). This theory paved the way for achieving gender equality between males and females. This theory provides efforts towards achieving gender equality. Liberal feminism claims that differences between women and men are not based on biology, which basically represents reproduction differences. Hence, women should have the same rights as men, including the same educational as well as employment opportunities (Enyew \& Mihrete, 2018). It is a theory that assumes that "inequity is a consequence of ignorance or prejudice and thus something that gradually can be modified through enlightened educational programs and corrective policies such as affirmative action"(Thompson, 2003, p. 14). According to this theory, both males and females are not different, and hence we should not treat differently under the law. Female should have the same rights, opportunities, and the same educational and work opportunities like as male.

In mathematics, still gender disparity have been found. Nepal is one of the developing country, still suffering from discrimination due to sex against girls in Nation and automatically in school and specifically in mathematics subject. In mathematical content, there is still misconception as one of the content area for male and another for female. In this study, feminist theory is applicable, it empowers teacher to give equal opportunities to both boys and girls while teaching each content area of mathematics. In this study liberal feminist theory focuses, girls are equally motivated and satisfied towards male dominated mathematical content area like as Geometry at secondary level. 


\section{Research Questions}

The following research questions were investigated in this study:

- Which mathematical content area do girls and boys prefer at secondary level?

- What type of mathematical content feel girls and boys important in their future life?

- Do the gender differencesexist in priorities of mathematical content?

\section{Methods of the Study}

In view of the fact that the main purpose of this study was to examine students' preferences on mathematical contents at secondary level. This study was based on post positivist paradigm (John W. Creswell, 2009). In this study, descriptive survey design (John W. Creswell, 2015) was employed to conduct research. Data of the study were acquired from secondary level students. I had taken two district Sindupalchok and Lalitpur from Bagmati Province. Moreover, one of the district Sindupalchok is located in Mountain region, while Lalitpur district is located in Valley region. From these two district, six schools(three from each district) were chosen randomly. The stratified random sampling design was employed to select students (boys and girls) from tenth grade in order to obtain a representative sample. Hence, the sample of this study consisted of 60 participants: 33 girls and 27 boys.

As for data collection, this study used self-developed questionnaire. The questionnaire was developed on the basis of two dimensions: one was about content area and another was about contents within each content area from grade IX mathematics curriculum. The questionnaire consisted 8 items from mathematical content area and 20 items from the contents within each content area. The 8 items of content area were constructed based on Satisfaction Likert scale ranges from Extremely Satisfied to Dissatisfied (Extremely Satisfied =5, Very Satisfied $=4$, Moderately Satisfied =3, Not Very Satisfied =2, and Dissatisfied =1). The 20 items of contents were constructed based on Important Likert scale ranges from Very Important to Unimportant(Very Important=5, Important=4, Moderate Important=3, Little Important=2, and Unimportant=1). For the reliability, Cronbach's Alpha reliability coefficient was calculated for each set of questionnaire: .778 for content area and .858 for contents within each content area. Moreover for validity, questionnaires were approved with the help of subject experts. Before administering survey questionnaire the purpose and rational of the study were clearly explained and consents were obtained from respondents. Then self- developed questionnaires were distributed to all respondents and collected data simultaneously. The data were coded and entered in SPSS (version 23) software and analyzed with the help of descriptive and inferential statistics such as mean, standard deviation, and t-test to obtain answer of the research questions.

\section{Results}

Boys and girls content area preferences. It was found that student preferences on different mathematical content area differently affected by gender. Girls may prefer one type of content area while boys prefer another type of content area in their mathematics learning process in secondary level. Regarding the research question first and third, we compared boys and girls preferences towards mathematical content area. The results of this content area are depicted in Table 1. 
Table 1: Comparison between Boys and Girls Mathematical Content Area Preferences

\begin{tabular}{lcrrrr}
\hline & \multicolumn{3}{c}{ Boys } & \multicolumn{3}{c}{ Girls } & \\
\cline { 2 - 5 } Content Area & Mean & S.D & Mean & S.D & P- value \\
\hline Set & 3.59 & 1.279 & 3.73 & 0.977 & 0.117 \\
Arithmetic & 3.15 & 1.027 & 3.12 & 0.857 & 0.275 \\
Mensuration & 3.04 & 1.055 & 3.27 & 1.153 & 0.463 \\
Algebra & 3.33 & 1.209 & 3.15 & 1.034 & 0.212 \\
Geometry & 2.85 & 1.262 & 3.3 & 1.159 & 0.658 \\
Trigonometry & 3.11 & 1.188 & 3.09 & 1.042 & 0.453 \\
Statistics & 3.37 & 1.043 & 3.7 & 1.237 & 0.358 \\
Probability & 3.41 & 1.047 & 3.03 & 1.262 & 0.608 \\
\hline Overall & 3.23 & 0.733 & 3.3 & 0.663 & 0.555 \\
\hline
\end{tabular}

The results from the table 1 shows that both boys (Overall mean=3.23, Std. $=0.73$ ) and girls (Overall mean $=3.29$, Std. $=0.66)$ are in general very satisfied in the different mathematical content area, showing that both mean greater than scale mean 3 in secondary level. Table 1 assures that both boys (Mean=3.59, Std.=1.279) and girls $($ Mean=3.73, Std. $=0.977)$ are in fact highly satisfied on the content area Set compared to other area of mathematics. Both boys and girls prefer Set is their favorite area, they did not feel difficult in comparison to other content area. Whereas, girls (Mean=3.03, Std.=1.262) are less satisfied on Probability area, they feel more difficult in comparison to other areas, while boys (Mean=2.85, Std. $=1.262$ ) are not very satisfied on the content area Geometry in comparison to other areas. This data indicated that boys' least preferable content area was Geometry,whereas girls' least preferable area was Probability in comparison to overall content area in mathematics. As a whole we can concluded that boy's slightly difficult mathematical content area was Geometry, while girl's slightly difficult content area became Probability in comparison to eight content areas.

Nonetheless, the result from the table 1 shows that girls slightly more satisfied and preferable content area were Set, Mensuration, Geometry, and Statistics compared to boys, while boys were slightly more satisfied and prefer the content area Arithmetic, Algebra, Trigonometry, and Probability compared to girls. The table also indicates that in all content area, both boys and girls are satisfied, their mean is greater than average scale 3 except Geometry, while boys are not satisfied in Geometry (Mean= 2.85, Std.=1.262) which is less than average scale 3. Both boys and girls are equally satisfied on the content area Trigonometry (Boys Mean=3.11, Std.=1.188; Girls Mean=3.09, Std.=1.042).

Table 1 also assures that there was no significance differences exist between boys and girls on the mathematical content area preferences $(\mathrm{P}=0.555 \square 0.05)$. Whereas, girl's mean is slightly greater than boys mean. They have similar level of satisfaction towards overall mathematical content area. Moreover, table also shows that in each content area Set, Arithmetic, Mensuration, Algebra, Geometry, Trigonometry, Statistics, and Probability there is no significant differences exist between boys and girls on the preferences of each content area. This result indicated that both boy and girls have similar level of preferences on mathematical content area, both boys and girls give equal value to the mathematics at secondary level. 
Boys' and girls' contents within mathematical content area preferences. There are different contents included within each content area. Students feel some contents are more useful for their later life while, some contents they feel useless in their future life. That's why they are not equally perceive all contents important while study mathematics. Table 2 shows both boys and girls responses towards importance of topics within each content area.

Table 2: Comparison between Boys and Girls Preferences of Contents within each Content Area

\begin{tabular}{|c|c|c|c|c|c|c|}
\hline \multirow{2}{*}{ Area } & \multirow{2}{*}{ Contents } & \multicolumn{2}{|c|}{ Male } & \multicolumn{2}{|c|}{ Female } & \multirow{2}{*}{ P-value } \\
\hline & & Mean & S.D & Mean & S.D & \\
\hline \multirow[t]{2}{*}{ Set } & Relation of group in Venn diagram & 2.96 & 1.315 & 3.18 & 1.158 & 0.32 \\
\hline & $\begin{array}{l}\text { Cardinality of sets and solution of } \\
\text { words problems }\end{array}$ & 2.63 & 1.149 & 3.42 & 0.936 & 0.178 \\
\hline \multirow[t]{3}{*}{ Arithmetic } & Profit and loss related problems & 4.67 & 0.679 & 4.75 & 0.622 & 0.404 \\
\hline & $\begin{array}{l}\text { Commission, discount, tax, } \\
\text { dividend related problems }\end{array}$ & 4.41 & 0.971 & 4.76 & 0.502 & 0.001 \\
\hline & Household related arithmetic & 4.15 & 0.864 & 4.36 & 0.994 & 0.405 \\
\hline \multirow[t]{3}{*}{ Mensuration } & $\begin{array}{l}\text { Area and volume related to cube, } \\
\text { cuboid, prism }\end{array}$ & 3.22 & 1.013 & 3.30 & 1.212 & 0.235 \\
\hline & Find area of real field or objects & 3.78 & 0.801 & 3.94 & 1.059 & 0.598 \\
\hline & $\begin{array}{l}\text { Project work related to real life } \\
\text { situation }\end{array}$ & 4.04 & 1.091 & 3.64 & 1.342 & 0.126 \\
\hline \multirow[t]{3}{*}{ Algebra } & Factorization / solving equation & 3.00 & 1.414 & 3.42 & 1.324 & 0.993 \\
\hline & Exponential equation & 2.74 & 1.457 & 3.39 & 1.171 & 0.196 \\
\hline & Ratio and proportion & 3.00 & 1.209 & 3.52 & 1.121 & 0.944 \\
\hline \multirow[t]{3}{*}{ Geometry } & Geometric construction & 3.52 & 1.252 & 3.48 & 0.906 & 0.052 \\
\hline & Experimental equations & 2.92 & 1.230 & 3.48 & 1.121 & 0.508 \\
\hline & Theoretical proof & 2.67 & 1.301 & 3.21 & 1.269 & 0.657 \\
\hline \multirow[t]{2}{*}{ Trigonometry } & Trigonometric relation on triangle & 3.07 & 1.357 & 3.82 & 1.211 & 0.425 \\
\hline & Solving trigonometric problems & 3.11 & 1.340 & 3.73 & 1.329 & 0.864 \\
\hline \multirow[t]{2}{*}{ Statistics } & Central tendency & 3.07 & 1.269 & 3.88 & 1.166 & 0.536 \\
\hline & Graphical representation & 3.44 & 1.251 & 3.33 & 1.384 & 0.284 \\
\hline \multirow[t]{2}{*}{ Probability } & Estimation of empirical probability & 3.37 & 1.182 & 3.58 & 1.146 & 0.875 \\
\hline & Probability of an event & 3.56 & 1.121 & 3.27 & 1.376 & 0.094 \\
\hline Overall & & 3.37 & 0.449 & 3.67 & 0.681 & 0.135 \\
\hline
\end{tabular}

Table 2 shows that both boys and girls in general feel all the mathematical contents within different content area were important for their later life (Boys Mean= 3.37, Std.= .449; Girls Mean $=3.67$, Std. $=.681$ ) as compared with scale mean 3. They both prefer all mathematical contents within each area for their future life. Whereas, little differences have been found in mean comparison in favor of girls. On the other hand, in regards to topics within content area, table 2 assures that every contents within Arithmetic area, both boys and girls feel highly important for their later life. In comparison to overall contents within each area, they both mostly prefer Arithmetic area for their future life. Moreover, in comparison of the different contents within Set 
area, girls feel all contents within Set are more important for their future life, while boys feel little important. Boys did not perceive contents within Set are important for later life. Interesting result is found in Algebra, boys are more satisfied in Algebra in comparison to girls (Table 1), but table 2 indicates "exponential equation" is the little important content for boys (Mean=2.74, Std.= 1.457), while girls feel this content is important (Mean=3.39, Std.=1.171) for future life. Mean differences have been found in other contents of Algebra, in "Factorization/Solving equation" and "Ratio and Proportion", boys feel slightly less important in comparison to girls.

Some contents within Geometry, like as "Experimental equations" and "Theoretical proof", girls feel slightly important than boys, boys only feel moderate important. Nonetheless, both boys and girls have almost same feelings on content "Geometric Construction", they feel important (Boys Mean= 3.52, Std.= 1.252; Girls Mean=3.48, Std.=0.906). Similarly, in other contents within Mensuration, Trigonometry, Statistics, and Probability, both boys and girls have almost similar feelings and they feel important and prefer these contents for their future life.

As shown in Table 2, it was found that there were not significant differences exist between boys and girls content preferenceswithin each content area, according to boys mean $=3.37$, girls mean $=$ 3.67, and $\mathrm{P}=0.135 \square 0.05$. According to the results, we could express that both boys and girls have similar expression about the importance of overall contents within each mathematical content area at secondary level. Similar results had found in each contents (topics) within mathematical area except one contents. However, the differences in each individual contents within every area (Set, Arithmetic, Mensuration, Algebra, Geometry, Trigonometry, Statistics, and Probability) between boys and girls were not statistically significant on which every p-value greater than 0.05 . Nonetheless, in one of the content as "commission, discount, tax, dividend related problems" within Arithmetic, we found significant differences exist between boys and girls feelings (male mean $=4.41$, female mean $=4.76, \mathrm{p}=0.001 \square 0.05$ ). However, as a whole we can say that both boys and girls have similar perception about contents importance in their future life.

\section{Discussion}

The main purpose of this study was to examine student's preferences on mathematical content area and contents within each content area. To obtain answer of the research questions, questionnaire were developed for student and results were analyzed. Now the results were discussed continuously.

It was revealed that, both boys' and girls' most preferable content area became Set, inverse result is found in NASA result of grade VIII in Nepal showed that students were weaker in Set (ERO, 2013). Similarly, this study found that boys preferred Algebra more than girls, while Girls prefer Geometry more than boys. Nonetheless, inverse result is found in (Uwineza et al., 2018) which revealed that boys preferred Geometry whereas girls preferred Algebra. The study by Bulut et al. (2010) also did not supports the finding and expressed that boys are more successful than girls in Geometry. The result indicated that girls least preferable and difficult content area is Probability, this finding was supported by the study of Okan and Arican (2020), which expressed that probability as the most difficult subject in the mathematics curriculum, while boys least preferable content area is Geometry. The Hence boys are Satisfied on the Probability, the finding is consistent with a previous study by (Bulut et al., 2010)which expressed that boys are more successful in Probability than girls. 
Gender Perspectives on Mathematical Content Preferences at Secondary Level / 51

This study also showed that, girls are more satisfied towards Statistics and prefer most in compare to boys. Inverse result is found in Chiesi and Primi (2015, February), which expressed that girls were less confident towards Statistics, feel more difficult, and negative attitude towards Statistics in comparison to boys. Boys slightly more satisfied on Arithmetic that result supports by (Le Grand, 2015) which revealed that boys perform better on numerical or arithmetical performance.

It was found that there were not significant differences exist between boys and girls on mathematical content area preferences and each individual content area preferences. Likewise, there were not statistically significant differences between boys and girls on mathematical contents within content area preferences. This result is not supported by previous NASA result of grade VIII which showed significant differences between boys and girls achievement in mathematics whereas in all content areas boys outperformed girls (ERO, 2015). But, in this study some content area, boys feel important, while in other content area girls feel important, both were equally motivated in learning mathematics. Liberal feminist theory also expressed that the differences between boys and girls did not based on biology, they are not different and we should not treat differently under the law (Thompson, 2003). That's why liberal feminist theory supports the findings of this study, girls equally satisfied as boys towards mathematics and prefer mathematics as important subject in their future life.

\section{Conclusion}

From the data of this study I found that both boys and girls are satisfying and enjoying on the content area Set. Whereas boys less preferable content area Geometry, while girls less preferable content area Probability in comparison to other content area, but the differences between boys and girls were not statistically significant. I found similar findings on contents within each content area, slightly differences found within contents between boys and girls but differences were not statistically significant. According to these results, I concluded that in the $21^{\text {st }}$ Century, girls equally valued mathematics, satisfied towards mathematics, motivated towards mathematics, feel every contents of mathematics would be important for their future life as boys.

\section{References}

Asante, K. O. (2010). Sex differences in mathematics performance among senior high students in Ghana. Gender and Behaviour, 8(2), 3279-3289.

Barkatsas, T., Law, H. Y., Seah, W. T., \& Wong, N. Y. (2019). The valuing of mathematics learning in schools: A gendered perspective. International Journal on Emerging Mathematics Education, 3(1), 41-56. doi:http://dx.doi.org/10.12928/ijeme.v3i1.11648

Bulut, S., Gür, B. S., \& Sriraman, B. (2010). Commentary 2 on feminist pedagogy and mathematics. In Theories of Mathematics Education (pp. 455-466): Springer, Berlin, Heidelberg.

Chambers*, E. A., \& Schreiber, J. B. (2004). Girls' academic achievement: Varying associations of extracurricular activities. Gender and Education 16(3), 327-346. doi:10.1080/0954 0250042000251470

Chiesi, F., \& Primi, C. (2015, February). Gender differences in attitudes toward statistics: Is there a case for a confidence gap? Paper presented at the CERME 9-Ninth congress of the European society for research in mathematics education, Prague, Coach Republic.

Creswell, J. W. (2009). Research design: Qualitative, quantitative, and mixed methods approaches (3rd Ed.). Thousand Oaks, CA: Sage.

Creswell, J. W. (2015). Educational research: Planning, conducting and evaluating quantiative and qualitative research. Noida: Pearson India Education Services Pvt. Ltd. 
Education Review Office. (2015). National Assessment of Student Achievement 2012 (Grade 3 and 5). Sanothimi: Education Review Office (ERO).

Education Review Office. (2016). National Assessment of Student Achievement 2015 (Grade 3 and 5). Sanothimi: Education Review Office (ERO).

Else-Quest, N. M., Hyde, J. S., \& Linn, M. C. (2010). Cross-national patterns of gender differences in mathematics: A meta-analysis. Psychological bulletin, 136(1), 103. doi: $10.1037 / \mathrm{a} 0018053$

Enyew, B. E., \& Mihrete, A. G. (2018). Liberal feminism: Assessing its compatibility and applicability in Ethiopia context. International Journal of Sociology and Anthropology, 10(6), 59-64.

ERO. (2013). Where are we now ? Student achievement in Mathematics, Nepali and Social Studies in 2011. Sanothimi: Education Review Office (ERO).

ERO. (2015). National Assessment of Student Achievement (NASA) 2013 (Grade 8: Mathematics, Nepali and Science). Sanothimi: Education Review Office (ERO).

Farooq, M. S., Chaudhry, A. H., Shafiq, M., \& Berhanu, G. (2011). Factors affecting students' quality of academic performance: A case of secondary school level. Journal of Quality and Technology Management, 7(2), 1-14.

Fryer Jr, R. G., \& Levitt, S. D. (2010). An empirical analysis of the gender gap in mathematics. American Economic Journal: Applied Economics, 2(2), 210-240.

Ganley, C. M., \& Lubienski, S. T. (2016). Mathematics confidence, interest, and performance: Examining gender patterns and reciprocal relations. Learning Individual Differences, 47, 182-193.

Hyde, J. S., Lindberg, S. M., Linn, M. C., Ellis, A. B., \& Williams, C. C. (2008). Gender similarities characterize math performance. Science, 321(5888), 494-495.

Le Grand, A. J. (2015). Gender differences in children's academic self-concept and achievement in math and reading. (Doctoral Dissertation). Northern Arizona University,

Letherby, G. (2003). Feminist research in theory and practice. McGraw-Hill Education (UK).

Lindberg, S. M., Hyde, J. S., Petersen, J. L., \& Linn, M. C. (2010). New trends in gender and mathematics performance: A meta-analysis. Psychological bulletin, 136(6), 1123. doi:10.1037/a0021276

Okan, K., \& Arican, M. (2020). Investigating Preservice Middle School Mathematics Teachers' Competencies in Statistics and Probability in Terms of Various Variables. Journal of Measurement and Evaluation in Education and Psychology, 11(1), 13-26. doi:10.21031/ epod.562586

Stoet, G., \& Geary, D. C. (2013). Sex differences in mathematics and reading achievement are inversely related: Within-and across-nation assessment of 10 years of PISA data. PloS One, 8(3), e57988.

Terry, G., \& Thapa, N. (2012). Gender audit of Nepal's school sector reform programme. Cambridge: DFID Human Development Resource Centre.

Thompson, A. (2003). Caring in context: Four feminist theories on gender and education. Curriculum Inquiry, 33(1), 9-65.

Uwineza, I., Rubagiza, J., Hakizimana, T., \& Uwamahoro, J. (2018). Gender attitudes and perceptions towards mathematics performance and enrolment in Rwandan secondary schools. Rwandan Journal of Education, 4(2), 44-56.

Zarza, J. A. (2018). Representations of feminist theory and gender issues in introductory-level sociology textbooks. (Doctoral Dissertations). Portland State University, 